\title{
Influence of day of oestrus on egg viability and comparative efficiency of in vitro fertilization in domestic cats in natural or gonadotrophin-induced oestrus
}

\author{
A. M. Donoghue ${ }^{1}$, L. A. Johnston ${ }^{1,2 *}$, K. L. Goodrowe ${ }^{1} \dagger$, \\ S. J. O'Brien ${ }^{2}$ and D. E. Wildt ${ }^{1}+$ \\ ${ }^{1}$ National Zoological Park, Smithsonian Institution, Washington DC 20008, USA; and ${ }^{2}$ Laboratory \\ of Viral Carcinogenesis, National Cancer Institute, Frederick Cancer Research and Developmental \\ Center, Frederick MD 21702, USA
}

\begin{abstract}
Thirty-six domestic cats received 100 iu hCG (i.m.) on day 1,2 or 3 of a natural, behavioural oestrus. Twenty-two anoestrous cats were injected with 150 iu pregnant mares' serum gonadotrophin (PMSG; i.m.) followed $84 \mathrm{~h}$ later by $100 \mathrm{iu} \mathrm{hCG.} \mathrm{Twenty-four} \mathrm{to} 26 \mathrm{~h}$ after hCG, all cats were examined laparoscopically to determine the number of ovarian follicles and to recover follicular eggs. Mature eggs were cultured with conspecific spermatozoa and examined $30 \mathrm{~h}$ later for cleavage. Within the natural oestrus group, cats on day 1 produced fewer $(P<0.05)$ follicles and total eggs than females on day 2 or 3 , and $88.9 \%$ of the day 1 eggs were degenerate or immature and unsuitable for in vitro fertilization (IVF). Although only $54.5 \%$ of the cats in the PMSG/hCG group exhibited overt oestrus, mean ( \pm SEM) numbers of follicles $(9.7 \pm 0.8)$ and oocytes recovered $(8.7 \pm 0.8)$ were at least twofold greater $(P<0.001)$ than those measured in the natural oestrus group $(3.7 \pm 0.6 ; 3.4 \pm 0.6$, respectively) or subgroups on day $2(3.7 \pm 0.4 ; 3.3 \pm 0.4)$ and day $3(5.7 \pm 0.8 ; 5.3 \pm 0.8)$. Overall, the proportion of eggs cleaving in vitro was similar $(P>0.05)$ between the natural oestrus group $(48.3 \%)$ and the PMSG/hCG group $(50.9 \%)$, but the latter group produced more than twice the number of embryos per donor. Embryo quality was unaffected $(P>0.05)$ by day of hormone treatment, and more than $80 \%$ of all two-cell embryos were rated good-to-excellent quality. In summary, there is a temporal relationship between day of sexual receptivity and follicular egg viability in the domestic cat: eggs on the first day of oestrus are not optimally responsive to an LH-like stimulus. There is also no evidence that PMSG/hCG treatment compromises egg quality or subsequent fertilizability in vitro. On the contrary, use of these gonadotrophins markedly improves overall IVF efficiency by increasing the total number of high quality embryos produced.
\end{abstract}

\section{Introduction}

One important element influencing fertilization and subsequent embryo development is the use and timing of exogenous gonadotrophins. For example, fertilization rate and resulting embryo quality are compromised in mated cats treated with commercial FSH (FSH-P; Burns-Biotec, Lincoln, NE) to induce oestrus (Goodrowe et al., 1988a). For this reason, we have relied upon an alternative gonadotrophin, pregnant mares' serum gonadotrophin (PMSG), in developing a felid in vitro fertilization (IVF) system. When administered before hCG, PMSG stimulates the production of multiple ovarian follicles

${ }^{*}$ Current address: Henry Doorly Zoo, 3701 South 10th Street, Omaha, NE 68107, USA

†Current address: Metro Toronto Zoo, West Hill, Ontario M1E 4R5, Canada. \$Author for correspondence.

Received 15 April 1992. containing eggs that readily cleave in vitro after insemination (Goodrowe et al., 1988b; Johnston et al., 1991a, b). However, egg viability appears closely related to the interval between administration of the two hormones; if the interval is too short or too long, egg quality and cleavage rate in vitro are markedly compromised (Goodrowe et al., 1988b; Donoghue et al., 1992).

The sensitivity of the domestic cat egg to the interval between the FSH-like and LH-like stimulus has been an incentive for considering other possible effects of exogenous gonadotrophins on IVF. It is well known that gonadotrophin therapies are associated with reduced fertilization rates in vivo and in vitro and poor embryonic development in mice (Maudlin and Fraser, 1977; Sato and Marrs, 1986), rats (Evans and Armstrong, 1984), rabbits (Fujimoto et al., 1974) and sheep (Moore et al., 1985). Problems frequently associated with exogenous gonadotrophin use in humans (ovarian hyperstimulation, cystic follicles, a perturbed endocrine milieu) have caused some to question whether IVF might be enhanced by using 
eggs from natural (nonhormone-stimulated) cycles (Messinis and Templeton, 1988; Osborn and Moor, 1988).

The domestic cat is an induced ovulator that exhibits distinct, overt signs of sexual receptivity for 5-7 consecutive days at 14-21 day intervals (see reviews, Goodrowe et al., 1989; Wildt, 1991). The female can mate on any day of oestrus, and repeated copulations on any of the first 3 days of oestrus elicit pituitary release of $\mathrm{LH}$ that causes ovulation and the formation of three to seven corpora lutea (Wildt et al., 1980, 1981; Schmidt et al., 1983). No data are available on the temporal aspects of intrafollicular egg viability during the course of oestrus in the cat.

This investigation had two inter-related objectives. First, the impact of day of oestrus on number of eggs, maturation and ability to fertilize in culture was evaluated to determine whether follicular eggs were functionally comparable during different days of early oestrus. Second, the data from naturally oestrous cats were compared with those collected from PMSG/hCGtreated females to determine which type of egg was the most efficient for IVF.

\section{Materials and Methods}

\section{Animals}

Adult domestic cats were housed alone (males) or in pairs (females) and given commercial dry cat food (Purina Cat Chow, St Louis, MO) and water ad libitum. The colony room contained no windows, but $12 \mathrm{~h}$ of fluorescent lighting were provided daily.

Oestrus detection, induction of ovarian activity, laparoscopy and egg recovery

Fifty-eight female cats were monitored individually and twice a day for overt signs of oestrus (i.e. increased vocalization, rubbing, lordosis and treading of the hind legs) (Michael, 1961; Wildt et al., 1981). The first 36 cats exhibiting overt sexual receptivity (the naturally oestrous group) received a single i.m. injection of 100 iu hCG (Sigma Chemical Co., St Louis, MO) on day $1(n=12), 2(n=12)$ or $3(n=12)$ of behavioural oestrus $(10: 00 \mathrm{~h})$. This specific hCG dose induces ovulation in a high proportion of naturally developing cat follicles (Wildt and Seager, 1978). The remaining 22 females were designated as the PMSG/hCG group. During periods of no oestrous behaviour, these cats were subjected to laparoscopy to confirm that the ovaries were inactive. Laparoscopy was performed as previously described (Wildt et al., 1977) under a surgical plane of anaesthesia induced and maintained with ketamine hydrochloride (Vetalar: Park Davis, Morris Plains, NJ; $20.0 \mathrm{mg} \mathrm{kg}^{-1}$ body weight, i.m.) and acepromazine maleate (Ayerst Labs, Rouses $\mathrm{Pt}, \mathrm{NY} ; 2.0 \mathrm{mg}$ $\mathrm{kg}^{-1}$, i.m.). During laparoscopy, an ancillary, graduated Verres needle was used to manipulate the reproductive organs intraabdominally to view all aspects of each ovary and to estimate follicle size. If no follicles $\geq 2 \mathrm{~mm}$ in diameter or corpora lutea were evident, each of these cats was injected i.m. with 150 iu PMSG (Sigma Chemical Co., St Louis, MO) followed 84 h later by 100 iu hCG (Sigma Chemical Co.). This PMSG dose was based on previous studies performed in our laboratory (Goodrowe $e t$ al., 1988b; Johnston et al., 1991a, b) and by others (Niwa et al., 1985). These cats were monitored twice a day for 5 consecutive days after PMSG administration for overt sexual receptivity to determine whether gonadotrophin treatment induced oestrous behaviour.

Twenty-four to $26 \mathrm{~h}$ after hCG, all females were subjected to laparoscopic egg collection (Goodrowe et al., 1988b) and the follicular contents aspirated into collection tubes containing modified Krebs-Ringer bicarbonate medium (mKRB) (Niwa et al., 1985; Tovoda and Chang, 1986) and $40 \mathrm{iu}$ heparin $\mathrm{ml}^{-1}$ $\left(37^{\circ} \mathrm{C}\right)$. Contents of the tubes for each individual cat were emptied into a $60 \mathrm{~mm} \times 15 \mathrm{~mm}$ plastic Petri dish and rinsed with $5 \mathrm{ml}$ of equilibrated medium. Recovered eggs were transferred to fresh $\mathrm{mKRB}$ and placed in a $5 \% \mathrm{CO}_{2}$ in air, humidified incubator $\left(37^{\circ} \mathrm{C}\right)$. After all collections were completed on a given day, each egg and its surrounding cumulus cell mass was assessed for maturational status on the basis of the following morphological criteria: (i) mature, if the corona radiata and cumulus oophorus cells were loosened and expanded; (ii) immature, if the egg had a tightly compacted corona radiata; or (iii) degenerate, if the egg appeared abnormal, pale or lacked an apparent corona radiata (Goodrowe et al., 1988b; Johnston et al., 1989, 1991a, b; Wildt, 1991). Only eggs designated as mature were inseminated in vitro. Within $2 \mathrm{~h}$ of collection, mature eggs were washed three times in mKRB under lightweight paraffin oil, placed in fresh mKRB (without heparin) and returned to the incubator.

\section{Collection and processing of spermatozoa}

Two male cats of proven fertility served as sperm donors and were used in rotation within groups and among subgroups to avoid the possibility of a male-specific effect (Fukui et al., 1988). Electroejaculates (Wildt et al., 1983) were subjected to swim-up processing (Goodrowe et al., 1988b). In brief, this involved transferring semen into a $1.5 \mathrm{ml}$ conical tube (Sarstedt Inc., Princeton, NJ, USA), diluting with an equal volume of $\mathrm{mKRB}$ and centrifuging for $8 \mathrm{~min}$ at $300 \mathrm{~g}$. The supernatant was aspirated and discarded, and $150 \mu \mathrm{l}$ of $\mathrm{mKRB}$ was layered slowly onto the resulting pellet and the spermatozoa allowed a $1 \mathrm{~h}$ swim-up $\left(22^{\circ} \mathrm{C}\right)$. The layered aliquot was aspirated and assessed objectively for sperm concentration and subjectively for percentage motility and forward progressive motility (rating of $0=$ no forward movement of spermatozoa to a rating of 5 = rapid, linear, forward movement; Wildt et al., 1983). Only swim-up aliquots containing spermatozoa with at least a $75 \%$ motility and 3.0 progressive motility rating were used for IVF. Spermatozoa were counted using a haemocytometer (Wildt et al., 1983) and diluted in mKRB to a final insemination concentration of $2 \times 10^{5}$ motile sperm cells $\mathrm{ml}^{-1}$.

\section{In vitro fertilization}

Up to ten mature eggs were placed in $100 \mu \mathrm{l}$ of sperm suspension (a total of $2 \times 10^{4}$ motile spermatozoa) under oil and co-cultured at $37^{\circ} \mathrm{C}$ in $5 \% \mathrm{CO}_{2}, 95 \%$ air atmosphere (Goodrowe et al., 1988b). After $12-18 \mathrm{~h}$ of culture, eggs were removed from fertilization dishes and washed in a $0.2 \%$ hyaluronidase 
Table 1. Number of ovarian follicles and recovered eggs in cats given hCG on the first, second or third day of natural oestrus

\begin{tabular}{lcccc}
\hline $\begin{array}{l}\text { Day of } \\
\text { oestrus* }\end{array}$ & $\begin{array}{c}\text { Number of follicles } \dagger \\
(\geq 2 \mathrm{~mm}) \text { per female }\end{array}$ & $\begin{array}{c}\text { Total number } \\
\text { of follicles }\end{array}$ & $\begin{array}{c}\text { Number of eggs }{ }^{\dagger} \\
\text { collected per female }\end{array}$ & $\begin{array}{c}\text { Total number } \\
\text { of eggs }\end{array}$ \\
\hline 1 & $1.7 \pm 0.6^{\mathrm{a}}$ & 20 & $1.5 \pm 0.6^{\mathrm{a}}$ & 18 \\
2 & $3.7 \pm 0.4^{\mathrm{b}}$ & 44 & $3.3 \pm 0.4^{\mathrm{b}}$ & 40 \\
3 & $5.7 \pm 0.8^{\mathrm{c}}$ & 68 & $5.3 \pm 0.8^{\mathrm{c}}$ & 63 \\
\hline
\end{tabular}

*When hCG was administered, $n=12$ cats for each group.

†Mean \pm SEM per female $24-26 \mathrm{~h}$ after $\mathrm{hCG}$.

a.b. Values within columns with different superscripts are significantly different $(P<0.05)$.

Table 2. Mean number ( \pm SEM) of eggs classified as mature, immature or degenerate in cats given hCG on the first, second or third day of natural oestrus or treated with PMSG and hCG

\begin{tabular}{lcccc}
\hline & \multicolumn{4}{c}{ Mean number of eggs classified as } \\
\cline { 2 - 5 } Treatment group & Mature (\%) & Immature (\%) & Degenerate (\%) \\
\hline Day 1 natural oestrus $(n=12)$ & $0.2 \pm 0.2^{\mathrm{a}}(11.1)$ & $0.2 \pm 0.2^{\mathrm{a}}(5.6)$ & $1.3 \pm 0.6^{\mathrm{a}}(83.3)$ \\
Day 2 natural oestrus $(n=12)$ & $1.6 \pm 0.5^{\mathrm{ab}}(47.5)$ & $0.6 \pm 0.4^{\mathrm{a}}(17.5)$ & $1.2 \pm 0.4^{\mathrm{a}}(35.0)$ \\
Day 3 natural oestrus $(n=12)$ & $3.4 \pm 0.7^{\mathrm{b}}(65.1)$ & $0.8 \pm 0.4^{\mathrm{a}}(15.9)$ & $1.0 \pm 0.3^{\mathrm{a}}(19.0)$ \\
PMSG/hCG $(n=22)$ & $7.3 \pm 1.0^{\mathrm{c}}(84.3)$ & $0.4 \pm 0.3^{\mathrm{a}}(5.0)$ & $1.0 \pm 0.6^{\mathrm{a}}(10.7)$ \\
\hline
\end{tabular}

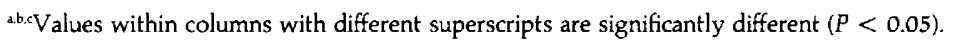

solution (Type 1-S from bovine tests, Sigma Chemical Co.) to remove cumulus cells and loosely attached spermatozoa. Eggs were returned to culture in $100 \mu \mathrm{l}$ drops of fresh medium, overlaid with oil and cultured for an additional $12-18 \mathrm{~h}$ before assessing fertilization. Fertilized eggs were those that cleaved to the two-cell stage of development within $30 \mathrm{~h}$ of insemination (Goodrowe et al., 1988b; Johnston et al., 1991a, b). Embryos cleaving to the two-cell stage or greater were assigned a quality grade according to previously published criteria (Goodrowe $e t$ al., 1988a; Johnston et al., 1991a, b). In brief, embryos of good or excellent quality were those that were perfectly symmetrical (or only slightly asymmetrical), spherical in shape and uniformly dark. Fair or poor quality embryos were those that were partially or severely degenerate, pale in colour or contained lysed blastomeres. All embryos were stained using a DNA-specific Hoechst stain (Goodrowe et al., 1988b) to confirm fertilization, and nuclei were counted.

\section{Statistical analysis}

Values are presented as means $\pm \mathrm{SEM}$. Differences in number of follicles or eggs collected between treatment groups were measured by analysis of variance using the Statistical Analysis System (SAS) general linear models program for factorial analysis (SAS, 1991). Treatment means were partitioned by least square means analysis. Chi-square $\left(\chi^{2}\right)$ analysis was used to compare the effect of natural oestrus versus PMSG/hCG treatment on the proportion of eggs fertilizing in vitro.

\section{Results}

Cats injected with hCG on day $I$ of natural oestrus produced fewer $(P<0.05)$ ovarian follicles and total eggs than females given hCG on days 2 and 3 (Table I). Because $>80 \%$ of the eggs collected from day 1 cats were classified as degenerate, too few eggs were available to test fertilizability in vitro (Table 2). Cats given hCG on day 3 produced more follicles and total eggs than did day 2 females $(P<0.05$; Table 1$)$, but the mean numbers of eggs categorized as mature, immature and degenerate were similar $(P>0.05)$ between these two subgroups (Table 2).

Of the 22 cats treated with PMSG, 12 (54.5\%) exhibited behavioural oestrus. However, PMSG-treated females produced more than twice the number of ovarian follicles and recovered eggs $(P<0.05)$ than the combined group of naturally oestrous cats (Table 3). More than $80 \%$ of the eggs from PMSG/hCGtreated females were rated as mature compared with $65.1 \%$ for day 3 naturally oestrous females (Table 2). Overall, cats injected with both gonadotrophins consistently produced more $(P<0.05)$ total follicles $(n=214$; mean $9.7 \pm 0.8$ per female $)$, total eggs ( $n=191 ; 8.7 \pm 0.8$ per female) and mature eggs ( $n=161 ; 7.3 \pm 1.0$ per female) than any of the naturally oestrous subgroups (Tables 1 and 2). There appeared to be no subjective differences in ovarian follicular morphology (size, colour or vascularity) between the naturally oestrous and PMSG/hCG groups.

The proportion of fertilized two-cell embryos was similar $(P>0.05)$ between the naturally oestrous group (29 of 60 
Table 3. Ovarian and egg characteristics and fertilization rates of natural oestrus versus PMSG and hCG stimulated cats

\begin{tabular}{lccc}
\hline Day of oestrus & $\begin{array}{c}\text { Mean* number } \\
\text { of follicles } \\
(\geq 2 \mathrm{~mm}) \text { per female }\end{array}$ & $\begin{array}{c}\text { Mean* number } \\
\text { of eggs collected } \\
\text { per female }\end{array}$ & $\begin{array}{c}\text { Number of } \\
\text { IVF embryos } \\
\text { per female } \dagger\end{array}$ \\
\hline Natural oestrus $(n=36)$ & $3.7 \pm 0.6^{\mathrm{a}}$ & $3.4 \pm 0.6^{\mathrm{a}}$ & $1.8 \pm 0.4^{\mathrm{a}}$ \\
PMSG/hCG $(n=22)$ & $9.7 \pm 0.8^{\mathrm{b}}$ & $8.7 \pm 0.8^{\mathrm{b}}$ & $4.3 \pm 0.8^{\mathrm{b}}$ \\
\hline
\end{tabular}

${ }^{*}$ Mean \pm SEM $24-26 \mathrm{~h}$ after hCG.

†Mean \pm SEM, includes only females from which eggs were inseminated (16 natural oestrus and I9 PMSGhCG treated queens).

a.bValues within columns with different superscripts are significantly different $(P<0.05)$.

mature eggs inseminated or $48.3 \%$ ) and the gonadotrophintreated group ( 82 of 161 mature eggs or $50.9 \%$ ). However, the latter group produced more than twice the number of total embryos per egg donor than the former (Table 3). Regardless, $85.4 \%$ of the resulting embryos in the naturally oestrous group were rated as good-to-excellent quality which was similar $(P>0.05)$ to $80.0 \%$ of the embryos achieving the same ratings in the PMSG/hCG group.

\section{Discussion}

This is the first study that has examined the relationship of day of overt oestrus, in vivo follicular response to an LH-like stimulus and subsequent egg quality in cats. Overall, there was a strong association between the first day of sexual receptivity and an inability of the follicular egg to respond to hCG. There was no disadvantage to using PMSG as a priming hormone for provoking folliculogenesis for subsequent IVF. On the contrary, using this particular exogenous gonadotrophin combined with hCG increased the overall number of mature eggs recovered without compromising subsequent fertilization in vitro or embryo quality.

Results from within the naturally oestrous group revealed that behavioural signs of oestrus were a poor index of the readiness of the follicular egg to respond to hCG. This issue has not been addressed previously, but cats are known to occasionally experience 'silent' oestrus (Graafian follicle development in the absence of overt sexual receptivity) (Wildt et al., 1978). In the study reported here, the total number of ovarian follicles and egg quality were enhanced if hCG administration was delayed until day 2 or 3 of oestrus. The cat will mate many times on any day of oestrus (Schmidt et al., 1983; Goodrowe et al., 1989), and these copulations are thought to (i) stimulate ovulation via the release of pituitary $\mathrm{LH}$ stores and (ii) ensure adequate numbers of spermatozoa at the site of fertilization (Wildt, 1991). On the basis of the few and poor quality of the day 1 eggs recovered in this study, it appears that the primary role of matings during early oestrus is to enhance pituitary gonadotrophin release to accentuate further follicular growth and egg maturation. This also probably explains why domestic cats (and other felid species) copulate so frequently during oestrus. Wildt et al. (1980) first demonstrated that cat ovarian follicles usually fail to rupture after only single matings, but sequential copulations prolong $\mathrm{LH}$ release which increases the proportion of cats ovulating. Parallel studies have also demonstrated that few spermatozoa are needed to achieve conception. Although a single domestic cat ejaculate normally contains $57-61 \times 10^{6}$ motile spermatozoa, as few as $6 \times 10^{6}$ spermatozoa inseminated in utero can result in conception (Howard et al., 1992). Frequent copulations during early oestrus therefore probably serve more to finalize folliculogenic events than to (i) cause immediate follicular rupture or (ii) ensure the presence of massive concentrations of deposited spermatozoa.

The finding that follicular development and egg integrity were compromised on the first day of natural oestrus was relevant to earlier observations concerning the sensitivity of the intrafollicular cat egg to exogenous PMSG/hCG. Extending the administration interval between these two gonadotrophins from 72 to $80 \mathrm{~h}$ decreases the proportion of degenerate eggs and increases the number of eggs fertilizing in vitro (Goodrowe et al., 1988b). If the interval between PMSG and hCG is extended beyond $80 \mathrm{~h}$ (up to 12 additional h), eggs continue to be of high quality, but viability declines (Donoghue et al., 1992). In the present study, if the interval between onset of oestrus and hCG administration was delayed for 24 (day 2) or 48 (day 3) $h$, then increasing numbers of follicles and mature, viable eggs were recovered. Taken together, these results demonstrate that timing of the LH-like stimulus in relation to naturally induced or gonadotrophin-induced folliculogenesis is important in predicting suitability of eggs for IVF. A poorly-timed hCG stimulus, even in naturally oestrous females, may interfere with eventual integrity of the egg and its viability. It is possible that the significant impact of the LH-like stimulus on egg function is closely related to the fact that the domestic cat is an induced ovulator. It is likely that this mating strategy serves a greater purpose in the domestic cat than simply causing follicular rupture. Copulations during early oestrus probably enhance follicular activity and subsequent egg integrity and fertilizability.

Results from the PMSG/hCG-treated group also confirmed that behavioural oestrus was uncoupled from either follicular or egg activity. More than $40 \%$ of these cats failed to exhibit overt sexual receptivity, yet mature eggs were recovered from 19 of $21(90.5 \%)$ females. This incidence of oestrus was consistent with an earlier study using the same PMSG dose (Goodrowe et al., 1988b). Although there were no apparent differences in gross follicular appearance, there was marked variation in the quality and maturation status of eggs from follicles on different 
days of natural oestrus. It therefore appears that there is little value in relying upon follicular appearance as a predictor of egg viability in cats.

Unlike sexual behaviour or follicular morphometry, a subjective estimate of maturation (on the basis of cumulus cell mass expansion) was an accurate index of potential egg fertilizing capacity. Eggs meeting maturation criteria and derived from either naturally oestrous or PMSG/hCG-primed cats could fertilize in vitro at comparable rates. Because polar body extrusion is so difficult to identify in the uniformly dark, lipidfilled cat egg (Goodrowe et al., 1988b), the degree of loosening and expansion of the corona radiata and associated cumulus mass continues to be the most reliable index of maturation (Goodrowe et al., 1988b; Johnston et al., 1991a, b). In this context, the cat egg is similar to that of the mouse (Gilula et al., 1978), human (Brackett, 1985) and pig (Motlik et al., 1986) in which these same criteria are convenient indices of egg maturity and fertilization potential.

As a gonadotrophin, PMSG is a potent stimulator of ovarian follicular development in cats. When given at a high dose or in sequential injections, PMSG causes ovarian hyperstimulation and the production of cystic follicles and abnormal endocrine profiles (Colby, 1970; Wildt et al., 1978; Cline et al., 1980). These adverse side effects are lessened using single doses $\leqslant 150$ iu (Niwa et al., 1985; Goodrowe et al., 1988b, 1989). In addition to excessive folliculogenesis, PMSG has been associated with questionable egg quality and relatively poor IVF rates in an array of laboratory and livestock species (Fujimoto et al., 1974; Maudlin and Fraser, 1977; Evans and Armstrong, 1984; Moore et al., 1985; Sato and Marrs, 1986). In contrast, we detected no adverse consequences of using PMSG, at the described dose, to accelerate follicular growth in cats. On the contrary, compared with results from naturally oestrous cats, the total number of eggs recovered was increased more than twice, and more PMSG-stimulated eggs met maturation criteria, thus increasing the total number of embryos produced per egg donor. The mechanism by which PMSG may contribute to egg maturation is unknown. However, a recent study compared follicular granulosa cell proliferation in spontaneously cyclic women with women treated with human menopausal gonadotrophin (hMG) (Gougeon and Testart, 1990). Granulosa cell histology revealed a higher mitotic index in the hMG group suggesting that this gonadotrophin may be promoting granulosa cell growth. It is possible that there is a similar PMSG-mediated mechanism in cats to enhance egg development.

If the practical purpose of IVF is to generate large numbers of viable embryos, then these results demonstrate conclusively that this objective can be achieved more efficiently in domestic cats by using PMSG rather than by relying upon naturally produced follicles. The total number of recoverable eggs is increased, and PMSG combined with hCG appears to promote intrafollicular egg maturation, thereby allowing ready sperm-egg interaction in vitro and the formation of cleaved embryos.

The authors thank S. Hurlbut, K. Cooper and T. Roth for assistance, P. Schmidt for providing culture medium and D. Donoghue for statistical analysis. We are grateful to K. James, R. Fry, M. Kriete and the National Institutes of Health Animal Center for management and veterinary care of the cats used in this study. This project was funded, in part, by grants from the National Institutes of Health (HD 23583) and Friends of the National Zoo.

\section{References}

Brackett BG (1985) In vitro oocyte maturation and fertilization Journal of Animal Science (Supplement 3) 61 14-24

Cline EM, Jennings LL and Sojka NJ (1980) Breeding laboratory cats during artificially induced estrus Laboratory Animal Science 30 1003-1005

Colby ED (1970) Induced estrus and timed pregnancies in cats Laboratory Animal Care 20 1075-1080

Donoghue AM, Johnston LA, Munson L, Brown JL and Wildt DE (1992) Influence of gonadotropin interval on follicular maturation, in vitro fertilization and subsequent luteal function in the domestic cat Biology of Reproduction $46972-980$

Evans G and Armstrong DT (1984) Reduction in fertilization rate in vitro of oocytes from immature rats induced to superovulate Journal of Reproduction and Fertility 70 131-135

Fujimoto S, Pahlavan N and Dukelow WR (1974) Chromosome abnormalities in rabbit preimplantation blastocysts induced by superovulation Journal of Reproduction and Fertility 40 177-181

Fukui Y, Glew AM, Gandolfi F. and Moor RM (1988) Ram-specific effects on in vitro fertilization and cleavage of sheep oocytes matured in vitro. Journal of Reproduction and Fertility 82 337-340

Gilula NB, Epstein ML. and Beers WH (1978) Cell-to-cell communication and ovulation: a study of the cumulus-oocyte complex Joumal of Cell Biology 78 58-75

Goodrowe KL, Howard JG and Wildt DE (1988a) Comparison of embryo recovery, embryo quality, oestradiol-17 $\beta$ and progesterone profiles in domestic cats at natural or induced oestrus journal of Reproduction and Fertility 82 553-561

Goodrowe KL, Wall RJ, O'Brien SJ, Schmidt PM and Wildt DE (1988b) Developmental competence of domestic cat follicular oocytes after fertilization in vitro Biology of Reproduction 39 355-372

Goodrowe KL, Howard JG, Schmidt PM and Wildt DE (1989) Reproductive biology of the domestic cat with special reference to endocrinology, sperm function and in vitro fertilization Joumal of Reproduction and Fertility Supplement 39 73-90.

Gougeon A and Testart J (1990) Influence of human menopausal gonadotropin on the recruitment of human ovarian follicles Fertility and Sterility $\mathbf{5 4}$ 848-852

Howard JG, Barone MA, Donoghue AM and Wildt DE (1992) The effect of preovulatory anaesthesia on ovulation in laparoscopically inseminated domestic cats Joumal of Reproduction and Fertility 96 175-186

Johnston LA, O'Brien SJ and Wildt DE (1989) In vitro maturation and fertilization of domestic cat follicular oocytes Gamete Research 24 343-356

Johnston LA, Donoghue AM, O'Brien SJ and Wildt DE (1991a) Culture medium and protein supplementation influence in vitro fertilization and embryo development in the domestic cat Joumal of Experimental Zoology 257 350-359

Johnston LA, Donoghue AM, O'Brien SJ and Wildt DE (1991b) Influence of temperature and gas atmosphere on in vitro fertilization and embryo development in the domestic cat Journal of Reproduction and Fertility 92 377-382

Maudlin I and Fraser LR (1977) The effect of PMSG dose on the incidence of chromosomal anomalies in the mouse embryo fertilized in vitro joumal of Reproduction and Fertility 50 272-280

Messinis IE and Templeton AA (1988) The endocrine consequences of multiple folliculogenesis Joumal of Reproduction and Fertility 36 27-31

Michael RP (1961) Observations upon the sexual behavior of the domestic cat (Felis catus L.) under laboratory conditions Behavior 18 1-24

Moor RM, Osborn JC and Crosby IM (1985) Gonadotrophin-induced abnormalities in sheep oocytes after superovulation Journal of Reproduction and Fertility 74 167-172

Motilik J, Fulka J and Flechon JE (1986) Changes in intercellular coupling between pig oocytes and cumulus cells during maturation in vivo and in vitro Joumal of Reproduction and Fertility 76 31-37

Niwa K, Ohara K, Hosoi Y and Iritani A (1985) Early events of in-vitro fertilization of cat eggs by epididymal spermatozoa Joumal of Reproduction and Fertility 74 657-660 
Osborn JC and Moor RM (1988) An assessment of the factors causing embryonic loss after fertilization in vitro Joumal of Reproduction and Fertility 36 $59-72$

Sato F and Marrs RP (1986) The effect of pregnant mare serum gonadotropin on mouse embryos fertilized in vivo and in vitro Journal of In Vitro Fertilization and Embryo Transfer 3 353-357

Schmidt PM, Chakraborty PK and Wildt DE (1983) Ovarian activity, circulating hormones and sexual behavior in the cat. II. Relationships during pregnancy, parturition, lactation and the postpartum estrus Biology of Reproduction 28 $657-671$

Statistical Analysis System (1991) SAS Institute Inc. Cary, North Carolina

Toyoda $Y$ and Chang MC (1986) Fertilization of rat eggs in vitro by epididymal spermatozoa and the development of eggs following transfer Joumal of Reproduction and Fertility 77 401-409

Wildt DE (1991) Fertilization in cats. In A Comparative Overview of Mammalian Fertilization pp. 299-328 Eds BS Dunbar and M O'Rand. Plenum Press, New York
Wildt DE and Seager SWJ (1978) Ovarian response in the estrual cat receiving varying dosages of hCG Hormone Research 9 130-136

Wildt DE, Kinney GM and Seager SWJ (1977) Laparoscopy for direct observation of internal organs in the domestic cat and dog American Joumal of Veterinary Research 38 1429-1432

Wildt DE, Kinney GM and Seager SWJ (1978) Gonadotropin induced cyclicity in the domestic cat Laboratory Animal Science 28 301-307

Wildt DE, Seager SWJ and Chakraborty PK (1980) Effect of copulatory stimuli on incidence of ovulation and serum luteinizing hormone in the cat Endocrinology 107 1212-1217

Wildt DE, Chan SYW, Seager SWJ and Chakraborty PK (1981) Ovarian activity, circulating hormones and sexual behavior in the cat. I. Relationships during the coitus-induced luteal phase and the estrous period without mating Biology of Reproduction 25 15-28

Wildt DE, Bush M, Howard JG, O'Brien SJ, Meltzer D, van Dyk A, Ebedes $H$ and Brand DJ (1983) Unique seminal quality in the South African cheetah and a comparative evaluation in the domestic cat Biology of Reproduction 29 1019-1025 